\title{
Common Inflammatory Disorders and Neoplasia of the lleal Pouch: A Review of Histopathology
}

\author{
David Hernandez Gonzalo ${ }^{a}$, Amy L. Collinsworth ${ }^{\mathrm{a}}$, Xiuli Liu ${ }^{\mathrm{a}}$, b
}

\begin{abstract}
Ileal pouch-anal anastomosis (IPAA) is the standard restorative procedure after proctocolectomy in patients with ulcerative colitis (UC) who require colectomy. The ileal pouch is susceptible to a variety of insults including mechanical injury, ischemia, fecal stasis, and infectious agents. In addition, the development of recurrent and idiopathic inflammatory bowel disease and neoplasia may occur in the ileal pouch. Although clinical, endoscopic, and radiographic examination can diagnose many ileal pouch diseases, histologic examination plays an essential role in diagnosis and management, particularly in cases with antibiotic refractory chronic pouchitis and pouch neoplasia.
\end{abstract}

Keywords: Inflammatory disorder; Neoplasia; Ileal pouch; Diagnosis; Pouchitis; Histopathology; Ulcerative colitis

\section{Introduction}

Over the last several decades, ileal pouch-anal anastomosis (IPAA) has evolved into the standard restorative procedure after proctocolectomy in ulcerative colitis (UC) and familial adenomatous polyposis syndrome (FAP). It is also used in patients with indeterminate colitis and in selected cases of Crohn's disease (CD) without small bowel involvement. A variety of diseases can affect ileal pouch and correct diagnosis of these diseases requires a synthesis of clinical, endoscopic, radiographic, and pathologic information $[1,2]$. Our knowledge of pouch diseases has been greatly expanded in recent years and it forms the basis of this review.

\section{Pouchitis}

Pouchitis is defined as a non-specific inflammation of the

Manuscript accepted for publication June 07, 2016

a Department of Pathology, Immunology and Laboratory Medicine, College of Medicine, University of Florida, Gainesville, FL, USA

${ }^{b}$ Corresponding Author: Xiuli Liu, Department of Pathology, Immunology and Laboratory Medicine, Gastrointestinal, Hepatic and Pancreaticobiliary Pathology, College of Medicine, PO Box 100275, Gainesville, FL 32610-0275, USA.Email: xiuliliu@uff.edu

doi: http://dx.doi.org/10.14740/gr706e ileal reservoir. Pouchitis is the most common complication of IPAA in patients with UC as a result of dysbiosis. It also occurs in FAP patients with IPAA but at a much lower rate [2]. It has been reported that the frequency of pouchitis is related to years of follow-up, occurring in up to $50 \%$ of patients 10 years after IPAA in large series from major referral centers [2-5]. It is most frequently diagnosed within the first year after ileostomy closure. Symptoms of pouchitis are non-specific and may include increased stool frequency and liquidity, abdominal cramping, urgency, tenesmus, and pelvic discomfort. In addition, rectal bleeding, fever, or extraintestinal manifestations may also occur in some patients. Patients suspected of having pouchitis should undergo pouchoscopy to document the presence of epithelial injury and inflammation and to obtain mucosal biopsies for histologic confirmation. For optimal histologic evaluation, biopsies should be taken from different locations including the neo-terminal ileum, pouch body, and rectal cuff. Specimens should be submitted separately either fresh in saline or fixed in $10 \%$ neutral buffered formalin.

The 18-point pouchitis disease activity index (PDAI) was proposed by Sandborn et al in 1994 [6] to diagnose pouchitis; it consists of three components: clinical symptoms, endoscopic findings, and pathologic findings. Each component has a maximal score of 6 points. The pathologic findings are based on the degree of neutrophilic inflammation and ulceration. The histologic score is assigned as follows: neutrophilic infiltration (1, 2, or 3 for mild, moderate + crypt abscess, and severe + crypt abscess, respectively) and mean ulceration per low-power field $(1,2$, or 3 for $<25 \%, 25-50 \%$, and $>50 \%$, respectively). Although the clinical use of the 18-point PDAI was later validated by other groups [1], some researchers have suggested that a combination of symptomatology and endoscopic findings may be adequate for diagnosing pouchitis [7]. However, symptomatology per se is not sufficient for diagnosing pouchitis in up to $25 \%$ of cases [1]. In cases with symptoms, a PDAI of $<7$ may suggest a diagnosis of irritable pouch syndrome in patients without cuffitis [8].

As with symptomatology or endoscopic findings, histological findings of pouchitis are non-specific. Histologic findings include acute inflammation with neutrophilic infiltration, crypt abscesses, erosion and ulceration, in association with a chronic inflammatory infiltrate $[9,10]$ (Fig. 1). The presence of inflammation alone in mucosal biopsies from an asymptomatic patient should not prompt the diagnosis of pouchitis and treatment with antibiotics.

Based on the clinical onset and duration of symptoms, pouchitis is classified into acute and chronic. The latter is fur- 


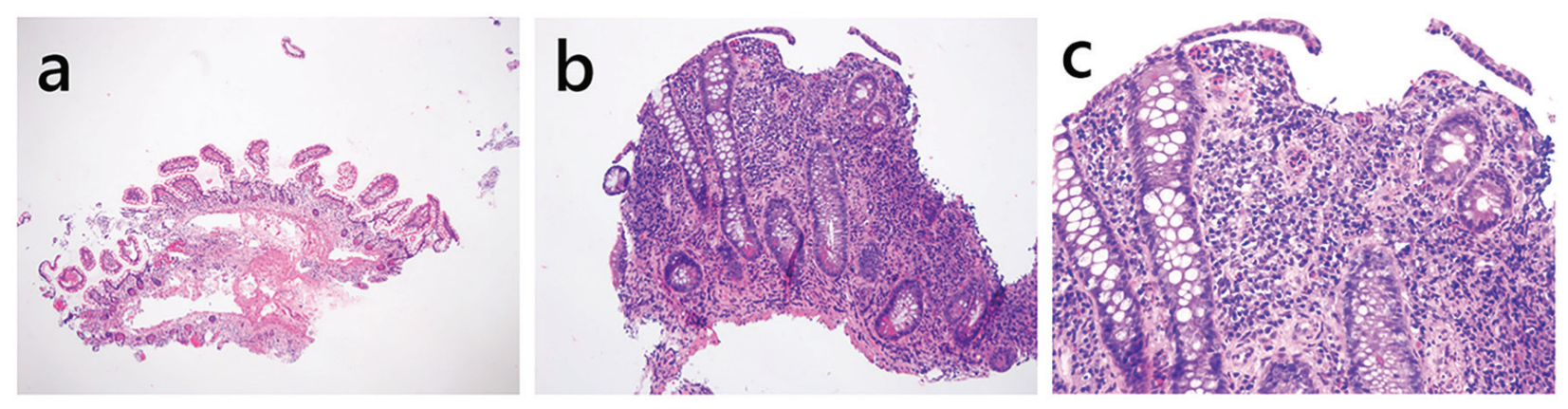

Figure 1. Histology of normal pouch (a) and pouchitis (b, c). (a) This pouch biopsy shows normal histology (H\&E stain, $\times 20)$. The small bowel mucosa demonstrates preserved and slender villous projection into the lumen. There are a few mononuclear inflammatory cells in the lamina propria but without expansion of the lamina propria. There is no basal lymphoplasmacytosis, neutrophilic inflammation, epithelial injury, erosion or ulceration. (b, c) This pouch specimen shows small bowel mucosa with villous blunting, erosion, chronic and active inflammation (b, H\&E, × 100; c, H\&E stain, $\times 200$ ), features of chronic pouchitis.

ther divided into antibiotic-responsive, -dependent, and -refractory depending upon the response to antibiotic treatment [11]. In one large series of IPAA, chronic pouchitis (defined as more than three attacks of pouchitis in a 12-month period) occurred in $15.9 \%$ of patients [2]. For patients with presumed chronic pouchitis who have persistent symptoms, alternative diagnoses should be considered along with histologic evaluation of biopsies to help narrow the differential diagnosis. If no specific etiologies are identified, the patients are considered to have chronic pouchitis and are usually treated with a long course of antibiotics.

\section{Secondary pouchitis with identifiable infectious agents}

Inflammatory bowel disease (IBD) is treated by immunosuppressive and biologic therapy creating an environment for opportunistic infections. Histologic examination of mucosal biopsies plays an important role in the diagnosis of certain types of infectious pouchitis.

\section{C. difficile pouchitis}

Ileal pouch C. difficile infection was initially reported by Mann et al (2003) [12]. Additional studies have revealed that $C$. difficile infection of the pouch is associated with male gender, pre-surgery left-sided colitis, pre-surgery antibiotic use, previous hospitalization, low serum immunoglobulin level and the presence of post-surgery mechanical intestinal complication $[13,14]$. Clinically, C. difficile infection of the pouch can be refractory or recurrent. The diagnosis mainly relies on symptomatology, endoscopic examination and detection of $C$. difficile toxins A and B by enzyme immunoassay or $C$. difficile toxin B gene by PCR assay in stools. Histologic evaluation can be helpful in identifying cases without typical endoscopic features. For example, some mild cases may only demonstrate subtle abnormalities such as edema, loss of vascularity and friability while some severe cases may only show ulceration without obvious pseudomembranes. Histologic findings in pouch $C$. difficile infection are non-specific and include acute inflammation and villous blunting/atrophy [15].

\section{Cytomegaloviral pouchitis}

Cytomegalovirus (CMV) infection in patients with IPAA has been recognized as an etiology of chronic pouchitis and one of the treatable causes of secondary pouchitis $[16,17]$. Clinical presentation of CMV pouchitis is non-specific and may include abdominal pain, increased stool frequency, and fecal incontinence, mimicking idiopathic/conventional pouchitis. However, patients with CMV pouchitis often have fever, which is not common in conventional pouchitis [18]. Endoscopic features of CMV pouchitis are non-specific and indistinguishable from conventional pouchitis. The diagnosis relies on the detection of CMV or its antigen. CMV can infect endothelium, stromal cells, and epithelial cells. CMV-infected cells often show typical features on routine hematoxylin and eosin (H\&E) stained sections; the cells are typically enlarged, two to fourfold larger than the surrounding normal cells, and contain eosinophilic intranuclear inclusions. The intranuclear inclusions are often eccentrically placed and surrounded by a clear halo, rendering the characteristic "owl's eye" appearance. Also commonly, those infected cells contain variably sized, eosinophilic, intracytoplasmic viral inclusions. Identification of typical CMV inclusions confirms the diagnosis of CMV pouchitis. In cases with possible CMV-infected cells, immunohistochemical staining for CMV antigen should be performed to confirm the diagnosis. However, caution should be taken when interpreting as some plasma cells may also show dense cytoplasmic staining. Only cells with dense, dark, nuclear staining should be interpreted as CMV-infected cells. Often, examination of serially sectioned levels will differentiate a CMV-infected cell from a plasma cell with dense cytoplasmic staining. The diagnosis of CMV pouchitis can also be made by other methods such as PCR analysis of CMV DNA in formalin-fixed and paraffinembedded pouch biopsy material [19]. Complimentarily or alternatively, blood can be analyzed for CMV DNA by PCR to detect CMV viremia in patients with pouchitis [18] before the initiation of anti-CMV treatment. 


\section{Fungal pouchitis}

\section{Candida pouchitis}

Rare cases of Candida pouchitis in patients with chronic antibiotic-refractory pouchitis have been reported [18], but Candida pouchitis as a separate disease entity has not been substantiated. In those reported cases, the presence of Candida species was limited to the surface of the epithelial layer in the pouch biopsy, without true tissue invasion. The use of special stains, such as Gomori methenamine silver (GMS) may help identify these organisms in the mucosal biopsy.

\section{Histoplasma capsulatum infection}

H. capsulatum infection of the ileal pouch has been reported in a patient with refractory $\mathrm{CD}$ of the pouch after undergoing a total colectomy for indeterminate colitis [20]. Pouch biopsy from this case showed patchy chronic active inflammation and numerous non-caseating epithelioid granulomas on $\mathrm{H} \& \mathrm{E}$ stain. GMS stain revealed rare 2 - $5 \mu \mathrm{m}$ intracellular yeast forms with morphology consistent with $H$. capsulatum. The patient also had positive urine and blood antigen tests for $H$. capsulatum antigen at the time of presentation.

Infectious pouchitis by multiple identifiable agents

Rare cases of pouchitis may be induced by multiple infections. For example, synchronous CMV and $C$. difficile infection of the pouch has been reported as a trigger for chronic pouchitis [21].

\section{Other secondary pouchitis}

\section{Ischemic pouchitis}

Ischemia may play an important role in the pathogenesis of pouchitis as well as distal ileitis or $\mathrm{CD}$ of the pouch. One early study has shown that pouch hypoperfusion is associated with pouch inflammation and local septic complications [22]. One small series proposed that endoscopic asymmetric, well demarcated, inflammation of the pouch appeared to represent ischemia-associated pouchitis [23]. Biopsies from ischemic pouchitis had higher frequency of extracellular hemosiderin or hematoidin deposits. The latter are characterized by extracellular golden yellow to yellow-brown crystalline pigment deposits on H\&E stained sections and are often present in the exudates or adjacent debris. Hematoidin deposits are not stained by Prussian blue, in contrast to hemosiderin deposits which are more granular and darker brown in color [23]. Of note, hemorrhagic necrosis, crypt atrophy, and lamina propria hyalinization, typical features of ischemic enteritis/colitis, are not present in ischemic pouchitis. Patients with ischemic pouchitis have some unique clinical features. For example, they are more likely to have subsequent abdominal surgeries after IPAA, more likely to have postoperative portal vein thrombi and less likely to respond to conventional antibiotic therapy. Although a diagnosis of ischemic pouchitis requires clinicopathologic correlation, identification of hemosiderin and/or hematoidin pigments may provide histologic clues to the diagnosis.

\section{Medication-associated pouchitis}

A variety of drugs can cause injury to the gastrointestinal tract, with non-steroidal anti-inflammatory drugs (NSAIDs) being the most notable. One previous report showed that the withdrawal of NSAID use alone resulted in a significant reduction in the PDAI score, PDAI endoscopy subscore and PDAI histology subscore in patients with a variety of ileal pouch disorders including chronic refractory pouchitis, acute pouchitis, cuffitis, and irritable pouch syndrome [24], suggesting that NSAIDs may induce pouchitis. This is further supported by one article reporting that sulindac use induced ulcerative pouchitis in one patient with FAP [25].

\section{Autoimmune pouchitis}

A subset of patients with idiopathic antibiotic-refractory chronic pouchitis may have no apparent etiology, respond only to corticosteroids, immunomodulators, or biologics, and demonstrate positive serum autoantibodies and concurrent immune-mediated disorders [26]. The term autoimmune pouchitis has been proposed for the chronic pouchitis in this subset of patients. Histologically, in comparison to antibioticresponsive pouchitis and normal pouches, this proposed entity has a significant increase in deep crypt apoptosis. With the use of an apoptotic score of 6 or greater (number of apoptotic cells per 10 high-power fields), this feature had a high specificity of $98.6 \%$ and a high positive predictive value of $90.9 \%$ [26]. Other features such as villous blunting, crypt distortion, ulceration, chronic inflammation, neutrophilic inflammation, deep crypt intraepithelial lymphocytosis, pyloric gland metaplasia (PGM), and goblet cell dropout are not diagnostically useful.

\section{Pouch Prolapse}

Prolapse of the ileal pouch is a rarely reported complication of IPAA with an overall incidence of $0.3 \%$ [27]. Prolapse of the pouch can be full thickness or superficial mucosal prolapse, and can be flat or polypoid [28]. Patients with pouch prolapse often experience external protrusion of tissue, sense of obstructed defecation, seepage, and pain [29]. The diagnosis of pouch prolapse often requires correlation with symptomatology and pouchoscopic examination. Biopsy may show intercrypt smooth muscle fibers, disrupted and thickened muscularis mucosae, and diamond shaped crypts, with or without mild diffuse chronic inflammation in the lamina propria [28]. In severe cases, erosion/ulceration can be seen. 


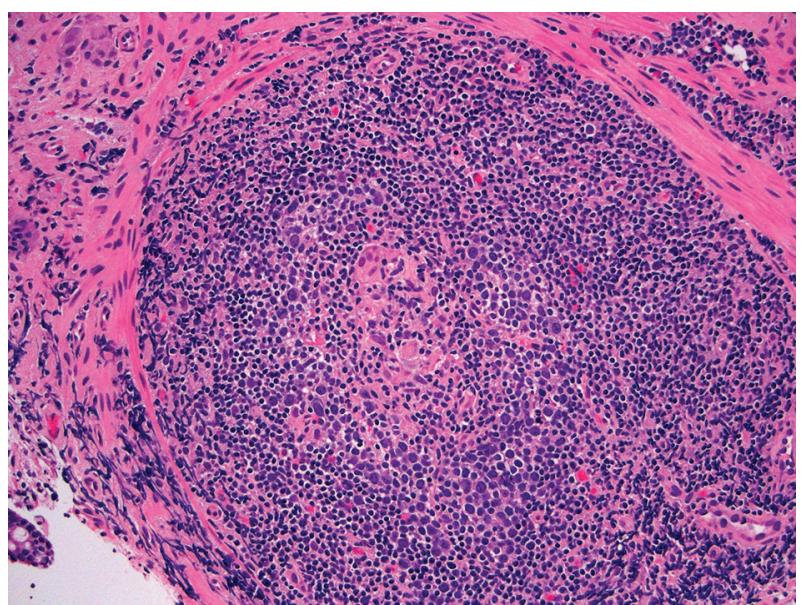

Figure 2. Crohn's disease of the pouch. This biopsy shows small bowel mucosa with mononuclear inflammatory expansion of the lamina propria (not included in the photo) and one well-formed non-caseating epithelioid granuloma in one lymphoid aggregate (H\&E stain, $\times 200$ ). In the right clinical setting, this finding supports the diagnosis of Crohn's disease of the pouch.

\section{CD of the lleal Pouch}

$\mathrm{CD}$ of the pouch is a relatively newly described entity. There is no consensus on terminology for $\mathrm{CD}$ that occurs in patients with IPAA. Multiple terms such as "CD of the pouch", "CD in IPAA", "Crohn's pouchitis", and "CD-like condition in ileal pouches" have been used in the literature to describe the scenario of an IPAA patient who has "characteristic" features of $\mathrm{CD}$, such as non-caseating, non-crypt-rupture-associated granulomas on histology, proximal small bowel involvement, and/or late-onset stricture or fistula. CD can occur in the ileal pouch constructed after proctocolectomy for presumed UC and indeterminate colitis in up to $7 \%$ of cases [30]. In contrast, patients with preoperative $\mathrm{CD}$ had up to $41-64 \%$ risk of developing recurrent $\mathrm{CD}$ in the afferent limb and/or the pouch $[31,32]$ and pouch failure rate was reported to be $13.3 \%$ in one large study [2].

Based on the background idiopathic IBD, two types of pouch $\mathrm{CD}$ have been recognized. $\mathrm{CD}$ of the pouch diagnosed in $\mathrm{CD}$ patients with presumed or inadvertently diagnosed as UC or indeterminate colitis (IC) upon re-reviewing of the colectomy specimens may be classified as early-onset $\mathrm{CD}$ of the pouch. In contrast, $\mathrm{CD}$ of the pouch developing de novo in patients after IPAA for UC and with a confirmed lack of evidence of $\mathrm{CD}$ upon histopathologic reassessment of the proctocolectomy specimens may be classified as late-onset $\mathrm{CD}$ of the pouch or de novo $\mathrm{CD}$ of the pouch $[33,34]$. Although outcomes in patients with delayed diagnosis are worse, there is still a $50 \%$ pouch retention rate at 10 years with good functional status of the pouch [33].

The diagnosis of pouch CD may be solely based on clinical features which include ulceration of the small bowel including the afferent limb without diffuse pouchitis persisting after at least 4 weeks of antibiotics. Stricture formation in the small bowel (including afferent limb), the pouch or pouch inlet combined with ulceration or inflammation in patients not taking NSAIDs was also regarded as CD. CD was also diagnosed in patients with fistulation following ileostomy closure. Of note, ulceration along staple lines should not be considered as $\mathrm{CD}$. In addition, patients developing a complication that might be indicative of $\mathrm{CD}$ (for example, fistula formation) occurring $<3$ months after ileostomy reversal should not be considered as $\mathrm{CD}$ on this basis alone [30]. Based on clinical features, $\mathrm{CD}$ of the pouch may be subclassified as inflammatory phenotype, fibrostenotic phenotype, and fistulizing phenotype [35].

Mucosal biopsy with histologic evaluation of the pouch only has a limited value in diagnosing $\mathrm{CD}$ of the pouch. The presence of non-caseating epithelioid granulomas, either in the lamina propria, submucosa, or in lymphoid aggregates, suggests a diagnosis of $\mathrm{CD}$ (Fig. 2). Unfortunately, only 10-12\% of patients with known $\mathrm{CD}$ of the pouch have granulomas on mucosal biopsy [35]. Granulomas secondary to crypt rupture or giant cell response to foreign material in biopsies taken from the suture line should not be used as evidence of CD. Further it is not clear whether isolated or "incidental" granulomas on biopsy should be treated or be offered pharmaceutical prophylaxis [34]. Other than granulomas, $\mathrm{CD}$ of the pouch does not exhibit specific histologic features. In two small studies, the presence of PGM was suggested to be a potential histologic marker for diagnosing $\mathrm{CD}$ of the pouch $[36,37]$; however, one other study showed that PGM can be found in both chronic antibiotic-refractory pouchitis and $\mathrm{CD}$ of the pouch and thus it cannot be used to diagnose $\mathrm{CD}$ of the pouch [38]. In the setting of IPAA, CD can also occur in any part of the gastrointestinal (GI) tract in addition to the distal afferent limb, pouch body, anal-transitional zone (ATZ), or perianal region, thus performing esophagogastroduodenoscopy with duodenal and/or stomach biopsy may yield additional information that supports the diagnosis [39].

Features of the common inflammatory disorders of the ileal pouch are summarized in Table 1.

\section{Pouch Neoplasia}

Pouch neoplasia includes a spectrum of neoplastic changes from dysplasia to adenocarcinoma. The risk of neoplasia in patients with UC and IPAA is small with a cumulative incidence at 5, $10,15,20$, and 25 years of $0.9 \%, 1.3 \%, 1.9 \%, 4.2 \%$, and $5.1 \%$ and this risk is not eliminated by mucosectomy [40]. In patients with IPAA after proctocolectomy for IBD, preoperative colorectal neoplasia increases risk for pouch neoplasia [40]. Currently, there is no recommendation regarding the surveillance for neoplasia in the pouch. In some institutes, the majority of patients undergo surveillance endoscopy every $1-3$ years at the discretion of the treating IBD specialist or colorectal surgeon. The endoscopic procedure includes inspection of the cuff or anal transitional zone (ATZ), pouch body, and afferent limb. During a typical diagnostic and/or surveillance pouch endoscopy, 2 - 6 pieces of biopsy are taken randomly from the afferent limb, ATZ and the pouch body and submitted in separate containers. Further, any abnormal mucosal area, such as polyps, deep ulcers, and stricture, needs to be sampled and submitted separately [40].

Histologic evaluation of surveillance biopsies plays an essential role in the management of patients with pouch neoplasia. Every pouch surveillance biopsy should be evaluated using 
Table 1. Summary of Clinicopathological Features of Common Inflammatory Disorders of the lleal Pouch

\begin{tabular}{|c|c|c|c|c|c|c|}
\hline Entity & $\begin{array}{l}\text { Duration of } \\
\text { symptoms }\end{array}$ & $\begin{array}{l}\text { Clinical response to } \\
\text { antibiotic treatment }\end{array}$ & $\begin{array}{l}\text { Pre-pouch } \\
\text { ileum }\end{array}$ & Pouch & Rectal cuff & Other features \\
\hline $\begin{array}{l}\text { Pouch } \\
\text { inflammation } \\
\text { of no clinical } \\
\text { significance }\end{array}$ & $\mathrm{N} / \mathrm{A}$ & $\begin{array}{l}\text { Should not be treated } \\
\text { with antibiotics }\end{array}$ & $+/-$ & $\begin{array}{l}\text { Variable degree of acute } \\
\text { and chronic inflammation }\end{array}$ & $+/-$ & Asymptomatic \\
\hline $\begin{array}{l}\text { Acute } \\
\text { pouchitis }\end{array}$ & $\begin{array}{l}\text { Acute onset, }<4 \\
\text { weeks symptom } \\
\text { duration }\end{array}$ & Antibiotic- response & $\begin{array}{l}\text { Variably } \\
\text { involved }\end{array}$ & $\begin{array}{l}\text { Acute inflammation, } \\
\text { crypt abscess, chronic } \\
\text { inflammation }(+/-)\end{array}$ & $+/-$ & \\
\hline $\begin{array}{l}\text { Chronic } \\
\text { pouchitis }\end{array}$ & $\begin{array}{l}>4 \text { weeks } \\
\text { symptom } \\
\text { duration and/or } \\
>3 \text { attacks in a } \\
12 \text {-month period }\end{array}$ & $\begin{array}{l}\text { Antibiotic- response, } \\
\text { antibiotic- dependent, } \\
\text { or antibiotic-refractory }\end{array}$ & $+/-$ & $\begin{array}{l}\text { Acute inflammation, } \\
\text { crypt abscess, chronic } \\
\text { inflammation, PGM (+/-) }\end{array}$ & $+/-$ & \\
\hline $\begin{array}{l}\text { Secondary } \\
\text { infectious } \\
\text { pouchitis }\end{array}$ & Variable & Antibiotic- refractory* & $+/-$ & $\begin{array}{l}\text { Acute inflammation, } \\
\text { crypt abscess, chronic } \\
\text { inflammation (+/-), PGM } \\
(+/-) \text {, granulomatous } \\
\text { inflammation (in some } \\
\text { fungal infection) }\end{array}$ & $+/-$ & $\begin{array}{l}\text { Viral inclusion, } \\
\text { fungal organisms } \\
\text { on special stain, or } \\
\text { positive stool } C \text {. } \\
\text { difficile toxin results }\end{array}$ \\
\hline $\begin{array}{l}\text { Ischemic } \\
\text { pouchitis }\end{array}$ & Variable & Antibiotic- refractory & $\begin{array}{l}\text { Relatively } \\
\text { normal }\end{array}$ & $\begin{array}{l}\text { Acute inflammation, } \\
\text { crypt abscess, chronic } \\
\text { inflammation (+/-), PGM } \\
(+/-) \text {, variable fibrosis }\end{array}$ & $\begin{array}{l}\text { Relatively } \\
\text { normal }\end{array}$ & $\begin{array}{l}\text { Asymmetric and } \\
\text { well demarcated } \\
\text { inflammation of the } \\
\text { pouch by endoscopy, } \\
\text { hematoidin or } \\
\text { hemosiderin deposits }\end{array}$ \\
\hline $\begin{array}{l}\text { Autoimmune } \\
\text { pouchitis }\end{array}$ & Variable & Antibiotic- refractory & $+/-$ & $\begin{array}{l}\text { Acute inflammation, } \\
\text { crypt abscess, chronic } \\
\text { inflammation, villous } \\
\text { blunting, PGM } \\
\text { (commonly present) }\end{array}$ & $+/-$ & $\begin{array}{l}\text { Prominent deep } \\
\text { crypt apoptosis }\end{array}$ \\
\hline $\begin{array}{l}\text { Crohn's } \\
\text { disease of } \\
\text { the pouch }\end{array}$ & Variable & Antibiotic- refractory & $\begin{array}{l}\text { Variably } \\
\text { involved }\end{array}$ & $\begin{array}{l}\text { Acute and chronic } \\
\text { inflammation, crypt } \\
\text { abscess, villous blunting, } \\
\text { PGM (common), non- } \\
\text { caseating granuloma } \\
\text { (10-12\% cases) }\end{array}$ & $\begin{array}{l}\text { Variably } \\
\text { involved }\end{array}$ & $\begin{array}{l}\text { Stricture or ulceration } \\
\text { away from staple } \\
\text { lines, and/or } \\
\text { fistula occurring } \\
\geq 3 \text { months after } \\
\text { ileostomy reversal, } \\
\text { involvement of upper } \\
\text { gastrointestinal tract }\end{array}$ \\
\hline $\begin{array}{l}\text { Idiopathic } \\
\text { pre-pouch } \\
\text { ileitis }\end{array}$ & Variable & Antibiotic- refractory & $\begin{array}{l}\text { Acute and } \\
\text { chronic } \\
\text { inflammation, } \\
\text { villous } \\
\text { blunting, PGM } \\
\text { (common) }\end{array}$ & Normal & Normal & \\
\hline Cuffitis & Variable & Antibiotic- refractory & $\begin{array}{l}\text { Relatively } \\
\text { normal }\end{array}$ & Relatively normal & $\begin{array}{l}\text { Chronic } \\
\text { active } \\
\text { colitis } \\
\text { pattern }\end{array}$ & \\
\hline
\end{tabular}

N/A: not applicable. PGM: pyloric gland metaplasia. ${ }^{*}$ C. difficile pouchitis may respond to anti-C. difficile antibiotic treatment.

the same criteria used for the surveillance colonic biopsy from patients with IBD. In the landmark paper by Riddell et al (1983) [41], a standardized classification of dysplasia was proposed for the evaluation of biopsy specimens from patients with IBD. The pathology report for pouch surveillance biopsy should clearly state the presence or absence of dysplasia. While most cases can be readily classified either as negative for dysplasia or positive for dysplasia, the authors acknowledged a category of "mucosa indefinite for dysplasia" defined as "epithelial changes impossible to be classified as either unequivocally negative or positive for dysplasia". Like colonic mucosal biopsies from IBD, the diagnosis of pouch dysplasia is based on the presence 


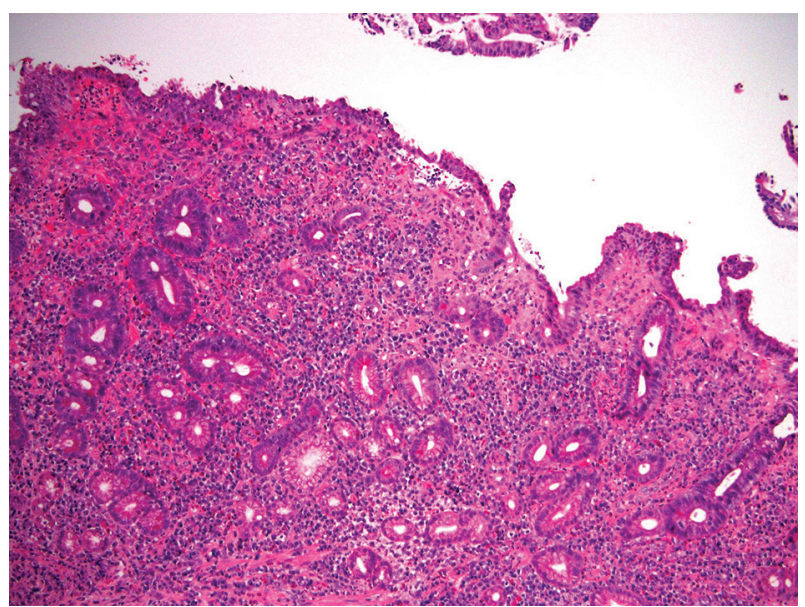

Figure 3. Pouch biopsy with epithelium negative for dysplasia. This biopsy shows small bowel mucosa with chronic active inflammation, architectural distortion, erosion, pyloric gland metaplasia, and regenerative epithelial changes (H\&E stain, $\times 100)$. A few glands show slightly enlarged, hyperchromatic, pencil-shaped nuclei. However, the aforementioned findings are seen in proximity to an erosion and there is at least partial maturation, thus, these changes should be interpreted as negative for dysplasia.

of a combination of microscopic features, including 1) architectural alterations exceeding that resulting from repair in chronic pouchitis, and 2) cytologic abnormalities, after excluding the possibility of inflammatory and regenerative changes that may affect the mucosa in chronic pouchitis.

\section{Epithelium negative for dysplasia}

In normal pouch mucosa, the villous architecture is maintained and the crypts are regularly spaced and touch the upper edge of the muscularis mucosae (Fig. 1a). Mononuclear inflammatory cells are present in the lamina propria, but should not noticeably expand it. Neither neutrophilic inflammation nor cytologic atypia are present. In normal ATZ biopsy, the epithelium can be small bowel mucosa or normal rectal mucosa with or without anal squamous epithelium and should lack inflammation or atypia. In some cases, the intestinal mucosa may show architectural abnormalities and metaplasia (PGM in small bowel mucosa or Paneth cell metaplasia in ATZ mucosa) without obvious inflammation or atypia (quiescent colitis equivalent). Sometimes, the biopsy may show a pattern of chronic active enteritis or chronic active colitis and in these cases, the damaged and regenerative epithelium may show villous blunting (for small bowel mucosa) and loss of mucin, features also seen in dysplastic cells. However, the presence of chronic active inflammation, surface and crypt epithelial damage, and the lack of significant nuclear enlargement, hyperchromasia, and pleomorphism should allow an interpretation of negative for dysplasia in this scenario (Fig. 3). The resolving or regenerative phase of pouchitis may pose the greatest diagnostic challenge with respect to the interpretation of dysplasia as there may no longer be neutrophilic crypt injury and the crypts may show varying degrees of nuclear enlargement, hyperchromasia, and nuclear stratifica-

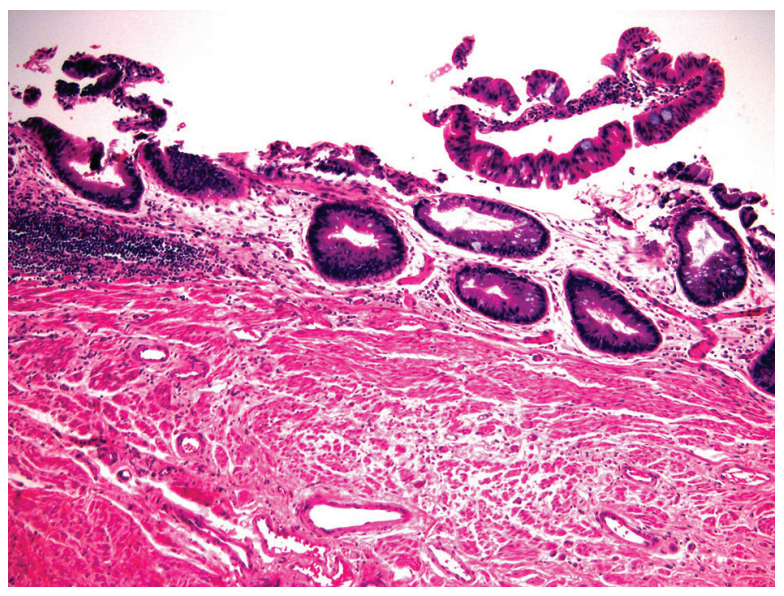

Figure 4. Pouch biopsy with low-grade dysplasia. This pouch biopsy shows low-grade dysplasia which is characterized by epithelium containing enlarged, hyperchromatic, pencil-shaped nuclei without surface maturation (H\&E stain, $\times 100$ ). This lesion does not show obvious nuclear pleomorphism or architectural complexity, features of high-grade dysplasia.

tion. Mitotic activity may be brisk. However, the presence of at least partial surface maturation (i.e., the nuclear enlargement and hyperchromasia in the regenerative crypts do not extend onto the surface mucosa), and the increased mononuclear inflammatory cells in the lamina propria are clues to regenerative changes. In difficult cases, knowing that the patient has been recently treated for an acute episode of pouchitis may be helpful.

\section{Epithelium positive for dysplasia}

This category is subdivided into low-grade dysplasia (LGD) and high-grade dysplasia (HGD) based on the degree of architectural and cytologic abnormalities.

\section{Positive for dysplasia, LGD}

Most biopsy specimens of LGD have crypts lined by epithelium with enlarged and hyperchromatic nuclei. Nuclear stratification is present but typically confined to the basal half of the epithelium. The nuclei in LGD maintain normal polarity; that is, their long axes are perpendicular to the basement membrane. Most cases of LGD do not exhibit surface nuclear maturation; in other words, the aforementioned atypical nuclear features should involve both crypt and surface epithelium (Fig. 4). In one report of 22 patients with initial diagnosis of pouch LGD, six $(27.3 \%)$ had persistence or progression after a median follow-up of 9.5 years [42].

\section{Positive for dysplasia, HGD}

HGD exhibits enlarged nuclei with marked nuclear hyperchromasia, pleomorphism, high nuclear to cytoplasmic ratio, and loss of nuclear polarity (Fig. 5). Abnormal mitotic figures 

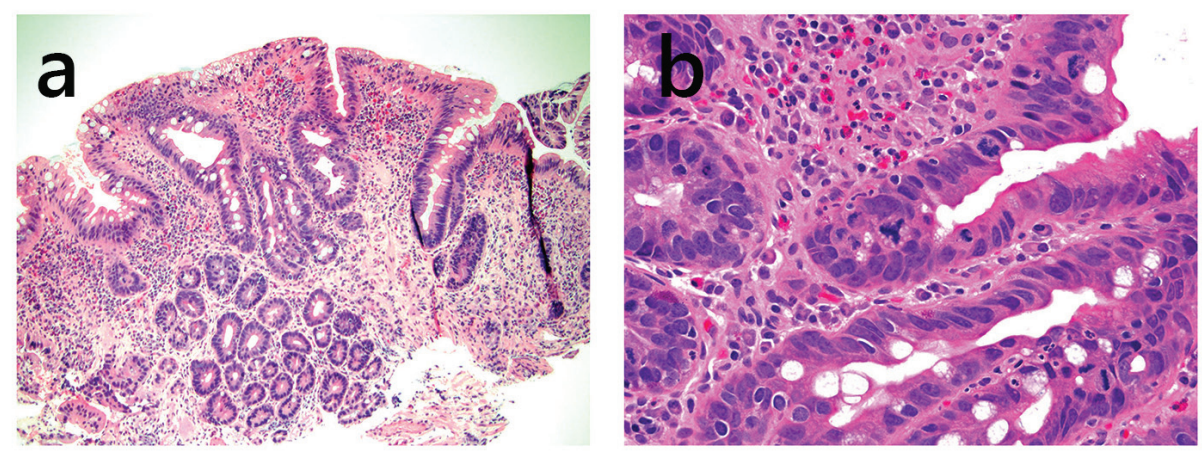

Figure 5. Pouch biopsy with high-grade dysplasia. This pouch biopsy shows glands with enlarged, hyperchromatic nuclei without surface maturation $(\mathrm{a}, \mathrm{H} \& \mathrm{E}$ stain, $\times 100)$. The glands show marked pleomorphism, high nuclear to cytoplasmic ratio, and abnormal mitotic figure $(b, H \& E$ stain, $\times 400)$.

may occasionally be seen (Fig. 5b). In addition to these cytologic/nuclear features, HGD may exhibit increased architectural complexity which may manifest as crowded or cribriform glands or villiform/papillary surface configuration. Like LGD, atypical nuclear features in HGD should involve both crypt and surface epithelium. In one report of 12 patients with pouch HGD, 25\% persisted or progressed after the initial management during a median follow-up of 5.4 years [42].

\section{Epithelial changes indefinite for dysplasia}

This category refers to ambiguous epithelial alterations that cannot be classified either as negative or positive for dysplasia with certainty. One study reported a rate of $2.3 \%$ indefinite for dysplasia in the ATZ and pouch in a cohort of 932 patients with IPAA for IBD [43]. Progression of IND to definite dysplasia is not common. For example, during a mean follow-up of 19.3 months, two (of $21,9.5 \%$ ) patients progressed: one patient developed LGD and one developed HGD [43]. In practice, there are a myriad of histologic patterns that may be categorized as indefinite for dysplasia. Most commonly, there are atypical cytologic features in the setting of florid inflammation or ulceration; in this setting, it may be difficult to distinguish regenerative changes from LGD or sometimes HGD. Another setting is the presence of severe nuclear abnormalities in the crypt bases when the surface mucosa cannot be evaluated due to ulceration or mechanical denudation. In addition, suboptimal embedding with tangential section or various cytologic features that arise as effects of suboptimal staining or fixation artifacts may lead to an interpretation of indefinite for dysplasia.

\section{Pouch adenocarcinoma}

Anatomic alterations resulting from the surgical procedure make the determination of the exact origin (pouch body vs. rectal cuff/ATZ) or cell lineage (intestine vs. anal gland) of pouch adenocarcinoma extremely difficult. In the largest series of 12 pouch and pre-pouch adenocarcinoma cases, eight patients had UC and four had CD including two with de novo $\mathrm{CD}$ of the pouch. The mean age at IBD diagnosis was 40 years and the mean duration from IBD diagnosis to pouch cancer was 25.6 years. The mean duration from pouch construction to pouch cancer was 10 years (range: 2 - 20 years) [44]. The tumor was located in the ATZ in eight cases (out of 12,67\%), in the pouch in one case, in the ATZ and pouch in two, and in non-specified peri-pouch region in one case. Pouch and peripouch adenocarcinoma has morphologic similarities to UC-associated colonic adenocarcinoma with a comparable frequency of tumor infiltrating lymphocytes $(66.7 \%)$, lack of dirty necrosis $(91.6 \%)$, mucin differentiation $(58.3 \%)$ (Fig. 6), signet ring cell differentiation $(25 \%)$, heterogeneity $(20 \%)$, well differentiation (25\%) (Fig. 6), and poor differentiation (41.6\%). Fifty percent of pouch and peri-pouch adenocarcinomas have Crohn-like reaction. Pouch and peri-pouch adenocarcinoma shows expression of CK20. Approximately $73 \%$ of pouch and peri-pouch adenocarcinoma cases had CDX2 expression and $55 \%$ CK 7 expression [44]. Of note, preoperative detection rate of pouch dysplasia in pouch surveillance biopsies in patients with pouch adenocarcinoma is low: out of nine patients who underwent surveillance, only three had dysplasia on surveillance biopsies [44].

\section{Other miscellaneous benign mass/lesion and malignancies in pouch}

Other benign mass/lesion can affect the pouch. For example, large pedunculated inflammatory cap polyp has been reported in the ileal pouch causing intermittent dyschezia [45]. Histologically, the polyp is composed of chronically and actively inflamed granulation tissue with exuberant regenerative and hyperplastic epithelium. Lymphoma arising in an ileal pouch after immunomodulatory therapy for IBD and squamous cell carcinoma of the ileal pouch have been reported $[40,46]$.

\section{Cuffitis and Pre-Pouch lleitis}

\section{Cuffitis}

During the stapled restorative proctocolectomy, a $1.5-2.0$ 

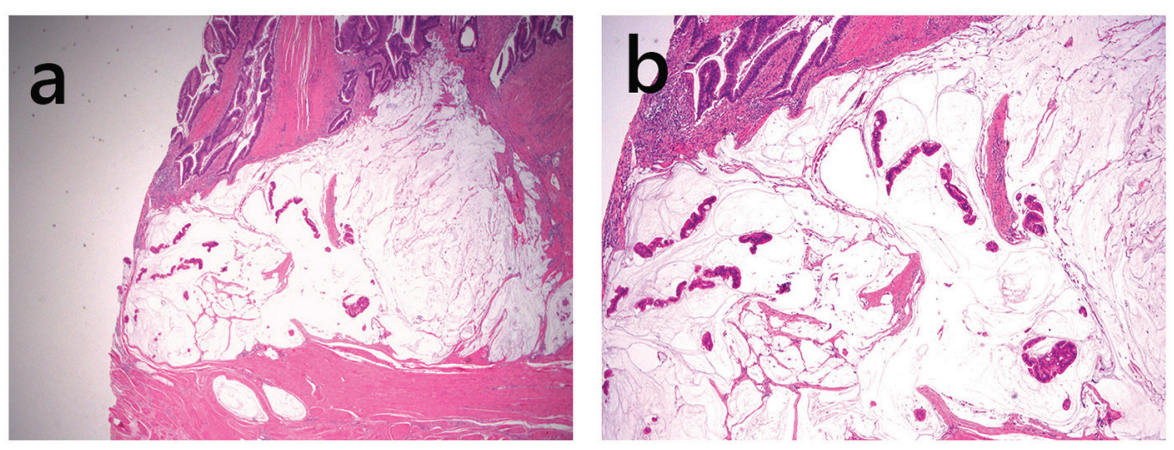

Figure 6. Pouch adenocarcinoma. This adenocarcinoma is well differentiated, contains abundant extracellular mucin, and invades the muscularis propria $(a, H \& E$ stain, $\times 20$; b, H\&E stain, $\times 40)$.

cm cuff of diseased columnar epithelium remains at the location proximal to the ATZ [47] and is at risk for developing symptomatic inflammation. Cuffitis has been conventionally considered a form of residual UC; it is defined as inflammation of the rectal cuff in the area between the anastomosis and dentate line on endoscopy and histology, with or without minimal inflammation of the pouch body [48]. It has histologic features similar to UC such as crypt distortion, crypt abscess, and neutrophilic and mononuclear inflammatory cell infiltration. According to the response to 5-aminosalicylate (5-ASA)/ steroid response, it can be classified as 5-ASA-responsive, -dependent, and -refractory cuffitis [48]. In patients with 5-ASA/ steroid-refractory cuffitis, subsequent investigation may reveal evidence of CD (32.8\%) or surgery-associated ATZ complications $(24.1 \%)$.

\section{Pre-pouch ileitis}

Inflammation in the neo-terminal ileum proximal to the pouch is observed in patients after restorative proctocolectomy, with or without association with pouchitis. Pouchitis-associated pre-pouch ileitis typically responds to antibiotic therapy. However, pre-pouch ileitis in the presence of normal pouch typically does not respond to antibiotics and is considered as idiopathic pre-pouch ileitis. Preoperative backwash ileitis has been reported to be a risk factor for the development of prepouch ileitis in one study [49]. Biopsy from the neo-terminal ileum in patients with pre-pouch ileitis shows a pattern similar to pouchitis including variable degrees of villous blunting, chronic inflammation in the lamina propria, and neutrophilmediated epithelial injury including variable degree of erosion/ulceration [49]. Crypt rupture-associated granulomas may be seen. Patients with idiopathic pre-pouch ileitis can develop strictures despite medical therapy and may require surgical resection and endoscopic dilatation of the stricture [49]. Other causes of pre-pouch ileitis include NSAIDs-related injury and ischemia induced by surgery $[30,49]$. In cases with ischemia as a potential etiology, there may be stricture, submucosal fibrosis, and capillary ectasia [49]. In some institutions, ulceration of the small bowel, including the afferent limb, without diffuse pouchitis which persists after at least 4 weeks of antibiotic therapy may prompt a diagnosis of pouch
$\mathrm{CD}[30]$.

\section{References}

1. Shen B, Achkar JP, Lashner BA, Ormsby AH, Remzi FH, Bevins CL, Brzezinski A, et al. Endoscopic and histologic evaluation together with symptom assessment are required to diagnose pouchitis. Gastroenterology. 2001;121(2):261-267.

2. Fazio VW, Kiran RP, Remzi FH, Coffey JC, Heneghan HM, Kirat HT, Manilich E, et al. Ileal pouch anal anastomosis: analysis of outcome and quality of life in 3707 patients. Ann Surg. 2013;257(4):679-685.

3. Fazio VW, Ziv Y, Church JM, Oakley JR, Lavery IC, Milsom JW, Schroeder TK. Ileal pouch-anal anastomoses complications and function in 1005 patients. Ann Surg. 1995;222(2):120-127.

4. Penna C, Dozois R, Tremaine W, Sandborn W, LaRusso N, Schleck C, Ilstrup D. Pouchitis after ileal pouch-anal anastomosis for ulcerative colitis occurs with increased frequency in patients with associated primary sclerosing cholangitis. Gut. 1996;38(2):234-239.

5. Shen B, Fazio VW, Remzi FH, Lashner BA. Clinical approach to diseases of ileal pouch-anal anastomosis. Am J Gastroenterol. 2005;100(12):2796-2807.

6. Sandborn WJ, Tremaine WJ, Batts KP, Pemberton JH, Phillips SF. Pouchitis after ileal pouch-anal anastomosis: a Pouchitis Disease Activity Index. Mayo Clin Proc. 1994;69(5):409-415.

7. Shen B, Achkar JP, Connor JT, Ormsby AH, Remzi FH, Bevins CL, Brzezinski A, et al. Modified pouchitis disease activity index: a simplified approach to the diagnosis of pouchitis. Dis Colon Rectum. 2003;46(6):748-753.

8. Shen B, Achkar JP, Lashner BA, Ormsby AH, Brzezinski A, Soffer EE, Remzi FH, et al. Irritable pouch syndrome: a new category of diagnosis for symptomatic patients with ileal pouch-anal anastomosis. Am J Gastroenterol. 2002;97(4):972-977.

9. Moskowitz RL, Shepherd NA, Nicholls RJ. An assessment of inflammation in the reservoir after restorative proctocolectomy with ileoanal ileal reservoir. Int J Colorectal Dis. 1986;1(3):167-174. 
10. Shepherd NA, Jass JR, Duval I, Moskowitz RL, Nicholls RJ, Morson BC. Restorative proctocolectomy with ileal reservoir: pathological and histochemical study of mucosal biopsy specimens. J Clin Pathol. 1987;40(6):601607.

11. Shen B, Remzi FH, Lavery IC, Lashner BA, Fazio VW. A proposed classification of ileal pouch disorders and associated complications after restorative proctocolectomy. Clin Gastroenterol Hepatol. 2008;6(2):145-158; quiz 124.

12. Mann SD, Pitt J, Springall RG, Thillainayagam AV. Clostridium difficile infection - an unusual cause of refractory pouchitis: report of a case. Dis Colon Rectum. 2003;46(2):267-270.

13. Seril DN, Shen B. Clostridium difficile infection in patients with ileal pouches. Am J Gastroenterol. 2014;109(7):941-947.

14. Seril DN, Ashburn JH, Lian L, Shen B. Risk factors and management of refractory or recurrent clostridium difficile infection in ileal pouch patients. Inflamm Bowel Dis. 2014;20(12):2226-2233.

15. Shen BO, Jiang ZD, Fazio VW, Remzi FH, Rodriguez L, Bennett AE, Lopez R, et al. Clostridium difficile infection in patients with ileal pouch-anal anastomosis. Clin Gastroenterol Hepatol. 2008;6(7):782-788.

16. Munoz-Juarez M, Pemberton JH, Sandborn WJ, Tremaine WJ, Dozois RR. Misdiagnosis of specific cytomegalovirus infection of the ileoanal pouch as refractory idiopathic chronic pouchitis: report of two cases. Dis Colon Rectum. 1999;42(1):117-120.

17. He X, Bennett AE, Lian L, Shen B. Recurrent cytomegalovirus infection in ileal pouch-anal anastomosis for ulcerative colitis. Inflamm Bowel Dis. 2010;16(6):903-904.

18. Navaneethan U, Shen B. Secondary pouchitis: those with identifiable etiopathogenetic or triggering factors. Am J Gastroenterol. 2010;105(1):51-64.

19. Casadesus D, Tani T, Wakai T, Maruyama S, Iiai T, Okamoto H, Hatakeyama K. Possible role of human cytomegalovirus in pouchitis after proctocolectomy with ileal pouch-anal anastomosis in patients with ulcerative colitis. World J Gastroenterol. 2007;13(7):1085-1089.

20. Lan N, Patil DT, Shen B. Histoplasma capsulatum infection in refractory Crohn's disease of the pouch on anti-TNF biological therapy. Am J Gastroenterol. 2013;108(2):281283.

21. Papaconstantinou I, Zampeli E, Dellaportas D, Giannopoulos C, Sotiropoulou M, Polymeneas G, Bamias G, et al. Synchronous cytomegalovirus and Clostridium difficile infection of the pouch: a trigger for chronic pouchitis? Clin J Gastroenterol. 2014;7(2):132-135.

22. Kienle P, Weitz J, Reinshagen S, Magener A, Autschbach F, Benner A, Stern J, et al. Association of decreased perfusion of the ileoanal pouch mucosa with early postoperative pouchitis and local septic complications. Arch Surg. 2001;136(10):1124-1130.

23. Shen B, Plesec TP, Remer E, Kiran P, Remzi FH, Lopez $\mathrm{R}$, Fazio VW, et al. Asymmetric endoscopic inflammation of the ileal pouch: a sign of ischemic pouchitis? Inflamm Bowel Dis. 2010;16(5):836-846.
24. Shen B, Fazio VW, Remzi FH, Bennett AE, Lopez R, Lavery IC, Brzezinski A, et al. Effect of withdrawal of nonsteroidal anti-inflammatory drug use on ileal pouch disorders. Dig Dis Sci. 2007;52(12):3321-3328.

25. Bertoni G, Sassatelli R, Bedogni G, Nigrisoli E. Sulindacassociated ulcerative pouchitis in familial adenomatous polyposis. Am J Gastroenterol. 1996;91(11):2431-2432.

26. Jiang W, Goldblum JR, Lopez R, Lian L, Shen B. Increased crypt apoptosis is a feature of autoimmune-associated chronic antibiotic refractory pouchitis. Dis Colon Rectum. 2012;55(5):549-557.

27. Joyce MR, Fazio VW, Hull TT, Church J, Kiran RP, Mor I, Lian L, et al. Ileal pouch prolapse: prevalence, management, and outcomes. J Gastrointest Surg. 2010;14(6):993997.

28. Blazeby JM, Durdey P, Warren BF. Polypoid mucosal prolapse in a pelvic ileal reservoir. Gut. 1994;35(11):16681669.

29. Ehsan M, Isler JT, Kimmins MH, Billingham RP. Prevalence and management of prolapse of the ileoanal pouch. Dis Colon Rectum. 2004;47(6):885-888.

30. Melton GB, Kiran RP, Fazio VW, He J, Shen B, Goldblum JR, Achkar JP, et al. Do preoperative factors predict subsequent diagnosis of Crohn's disease after ileal pouchanal anastomosis for ulcerative or indeterminate colitis? Colorectal Dis. 2010;12(10):1026-1032.

31. Shen B, Patel S, Lian L. Natural history of Crohn's disease in patients who underwent intentional restorative proctocolectomy with ileal pouch-anal anastomosis. Aliment Pharmacol Ther. 2010;31(7):745-753.

32. Le Q, Melmed G, Dubinsky M, McGovern D, Vasiliauskas EA, Murrell Z, Ippoliti A, et al. Surgical outcome of ileal pouch-anal anastomosis when used intentionally for well-defined Crohn's disease. Inflamm Bowel Dis. 2013;19(1):30-36.

33. Melton GB, Fazio VW, Kiran RP, He J, Lavery IC, Shen B, Achkar JP, et al. Long-term outcomes with ileal pouch-anal anastomosis and Crohn's disease: pouch retention and implications of delayed diagnosis. Ann Surg. 2008;248(4):608-616.

34. Li Y, Wu B, Shen B. Diagnosis and differential diagnosis of Crohn's disease of the ileal pouch. Curr Gastroenterol Rep. 2012;14(5):406-413.

35. Shen B, Fazio VW, Remzi FH, Bennett AE, Lavery IC, Lopez R, Brezinski A, et al. Clinical features and quality of life in patients with different phenotypes of Crohn's disease of the ileal pouch. Dis Colon Rectum. 2007;50(9):1450-1459.

36. Agarwal S, Stucchi AF, Dendrinos K, Cerda S, O'Brien MJ, Becker JM, Heeren T, et al. Is pyloric gland metaplasia in ileal pouch biopsies a marker for Crohn's disease? Dig Dis Sci. 2013;58(10):2918-2925.

37. Weber CR, Rubin DT. Chronic pouchitis versus recurrent Crohn's disease: a diagnostic challenge. Dig Dis Sci. 2013;58(10):2748-2750.

38. Kariv R, Plesec TP, Gaffney K, Lian L, Fazio VW, Remzi FH, Lopez R, et al. Pyloric gland metaplasia and pouchitis in patients with ileal pouch-anal anastomoses. Aliment Pharmacol Ther. 2010;31(8):862-873. 
39. Shen B, Wu H, Remzi F, Lopez R, Shen L, Fazio V. Diagnostic value of esophagogastroduodenoscopy in patients with ileal pouch-anal anastomosis. Inflamm Bowel Dis. 2009;15(3):395-401.

40. Kariv R, Remzi FH, Lian L, Bennett AE, Kiran RP, Kariv Y, Fazio VW, et al. Preoperative colorectal neoplasia increases risk for pouch neoplasia in patients with restorative proctocolectomy. Gastroenterology. 2010;139(3):806812, 812 e801-802.

41. Riddell RH, Goldman H, Ransohoff DF, Appelman HD, Fenoglio CM, Haggitt RC, Ahren C, et al. Dysplasia in inflammatory bowel disease: standardized classification with provisional clinical applications. Hum Pathol. 1983;14(11):931-968.

42. Wu XR, Remzi FH, Liu XL, Lian L, Stocchi L, Ashburn J, Shen B. Disease course and management strategy of pouch neoplasia in patients with underlying inflammatory bowel diseases. Inflamm Bowel Dis. 2014;20(11):20732082.

43. Liu ZX, Liu XL, Patil DT, Lian L, Kiran RP, Remzi FH, Ni RZ, et al. Clinical significance of indefinite for dysplasia on pouch biopsy in patients with underlying inflammatory bowel disease. J Gastrointest Surg. 2012;16(3):562571.
44. Jiang W, Shadrach B, Carver P, Goldblum JR, Shen B, Liu X. Histomorphologic and molecular features of pouch and peripouch adenocarcinoma: a comparison with ulcerative colitis-associated adenocarcinoma. Am J Surg Pathol. 2012;36(9):1385-1394.

45. Obusez EC, Liu X, Shen B. Large pedunculated inflammatory cap polyp in an ileal pouch causing intermittent dyschezia. Colorectal Dis. 2011;13(9):e308-309.

46. Schwartz LK, Kim MK, Coleman M, Lichtiger S, Chadburn A, Scherl E. Case report: lymphoma arising in an ileal pouch anal anastomosis after immunomodulatory therapy for inflammatory bowel disease. Clin Gastroenterol Hepatol. 2006;4(8):1030-1034.

47. Thompson-Fawcett MW, Mortensen NJ. Anal transitional zone and columnar cuff in restorative proctocolectomy. Br J Surg. 1996;83(8):1047-1055.

48. Wu B, Lian L, Li Y, Remzi FH, Liu X, Kiran RP, Shen B. Clinical course of cuffitis in ulcerative colitis patients with restorative proctocolectomy and ileal pouch-anal anastomoses. Inflamm Bowel Dis. 2013;19(2):404-410.

49. Bell AJ, Price AB, Forbes A, Ciclitira PJ, Groves C, Nicholls RJ. Pre-pouch ileitis: a disease of the ileum in ulcerative colitis after restorative proctocolectomy. Colorectal Dis. 2006;8(5):402-410. 